J. Clin. Chem. Clin. Biochem.

Vol. 20, 1982, pp. 147-150

\title{
Faecal Chymotrypsin - A New Photometric Method Using N-Acetyl-L-tyrosine Ethyl Ester as Substrate ${ }^{1}$ )
}

\author{
By R. Schlaeger and A. Röhr \\ Central Laboratory, Allgemeines Krankenhaus Wandsbek, Hamburg
}

(Received October 29/December 1, 1981)

Summary: A photometric method for chymotrypsin is proposed, using the substrate $N$-acetyl- $L$-tyrosine ethyl ester, which is already used in the titrimetric procedure. Hydrolysis of the ester bond produces equal amounts of ethanol and acetyltyrosine, the latter being measured in the titrimetric method. The ethanol can easily be measured by the alcohol dehydrogenase method in the trichloroacetic acid supernatant. Suitable test conditions are reported.

\section{Chymotrypsin im Stuhl - eine neue photometrische Methode mit dem Substrat Acetyltyrosylethylester}

Zusammenfassung: Es wird vorgeschlagen, das im titrimetrischen Verfahren bewährte Substrat N-Acetyl-L-tyrosylethylester für eine photometrische Methode zu verwenden. Nach hydrolytischer Spaltung der Esterbindung wird neben der titrierbaren Säure Acetyltyrosin äquimolar Ethanol frei. Dieses kann einfach im klaren Trichloressigsäureüberstand enżymatisch gemessen werden. Die geeigneten Meßbedingungen werden beschrieben.

\section{Introduction}

The determination of faecal chymotrypsin is generally accepted as the first step in evaluating the exocrine pancreatic function. Until now, faecal chymotrypsin activity has been measured reliably only by following titrimetrically the hydrolysis of $\mathrm{N}$-acetyl- $L$-tyrosine ethyl ester in a pH-stat (2).

Several different photometric procedures, using amide substrates have been suggested for use in less specially equipped routine laboratories. Since the enzyme is bound to stool particles in varying amounts from 50 to almost $100 \%$ (3), methods using the clear faecal supernatant (4) are not applicable. The substrate must be incubated with uncentrifuged stool suspension before the coupling reaction can be carried out in the clear supernatant after àcid precipitation and centrifugation (5). The results of these methods, however, do not correlate well with the results of the titrimetric test. Photometric procedures give consistently lower faecal chymotrypsin concentrations even if carried out with pure bovine chymotrypsin as standard for calibration. According to our current

\footnotetext{
1) Preliminary results have been reported at the Joint Congress of the Scandinavian and German Societies of Clinical Chemistry in Hamburg, October 8-11, 1980 (1).
}

results using the amide substrate $\mathrm{N}$-benzoyl- $L$-tyrosyl$p$-aminobenzoic acid (6), part of the reaction product $p$-aminobenzoic acid remained bound to faecal particles, resulting in lower concentrations after centrifugation.

This would offer a possible explanation for the bad correlation between titrimetric and photometric methods found with faecal material and the good agreement between these two methods when assaying duodenal fluid (7). We therefore developped a photometric test that makes use of the substrate $\mathrm{N}$-acetyl- $L$ tyrosine ethyl ester (already used in the titrimetric procedure), assuming that "particle binding" would not occur for the small molecule ethanol.

\section{Materials and Methods}

All reagents were p.a. grade from Merck Darmstadt (FRG). Buffer: Tris $0.15 \mathrm{~mol} / 1, \mathrm{NaCl} 0.5 \mathrm{~mol} / 1, \mathrm{CaCl}_{2} 0.08 \mathrm{~mol} / 1$, adjusted to $\mathrm{pH} 9.0$ with $\mathrm{HCl}$.

Substrate solution: $5 \mathrm{~g} \mathrm{~N}$-acetyl-L-tyrosine ethyl ester (ATEE, Merck 83) are dissolved in $100 \mathrm{ml}$ dimethylsulfoxide (DMSO, Merck 2950).

Precipitant: Trichloroacetic acid $3.3 \mathrm{~mol} / 1$. 
Chymotrypsin standard: Crystallized, lyophilized bovine chymotrypsin (Merck 2307). A stock solution of $1 \mathrm{~g} / 10.15 \mathrm{~mol} / 1 \mathrm{NaCl}$ is prepared and frozen in small portions. Before use it is further diluted 200 fold to give a final concentration of $5 \mathrm{mg} / \mathrm{l}$.

Ethanol test: Alcohol dehydrogenase method (8). Reagents e.g. Testcombination "Blood alcohol" (Boehringer Mannheim 123960 ).

Stool samples of about $5 \mathrm{~g}$ are collected on three different days and stored refrigerated up to 1 week at $8-4{ }^{\circ} \mathrm{C}$ until analysis.

\section{Results and Discussion}

Ethanol as a parameter of the enzymatic hydrolysis of $\mathrm{N}$-acetyl- $L$-tyrosine ethyl ester

Chymotrypsin hydrolyses 1 molecule of $\mathrm{N}$-acetyl- $L$ tyrosine ethyl ester to give 1 molecule of $\mathrm{N}$-acetyltyrosine and 1 molecule of ethanol. Figure 1 shows that under suitable experimental conditions the titratable acid equivalent and free alcohol agree with the theoretical stoichiometric relationship of 1:1. Faecal material and pure bovine chymotrypsin give similar results (for details see legend to fig. 1).

While the accumulation of $\mathrm{N}$-acetyltyrosine can be determined continuously by alkali titration, the amount of released ethanol can only be measured as the final concentration. In a continuous photometric

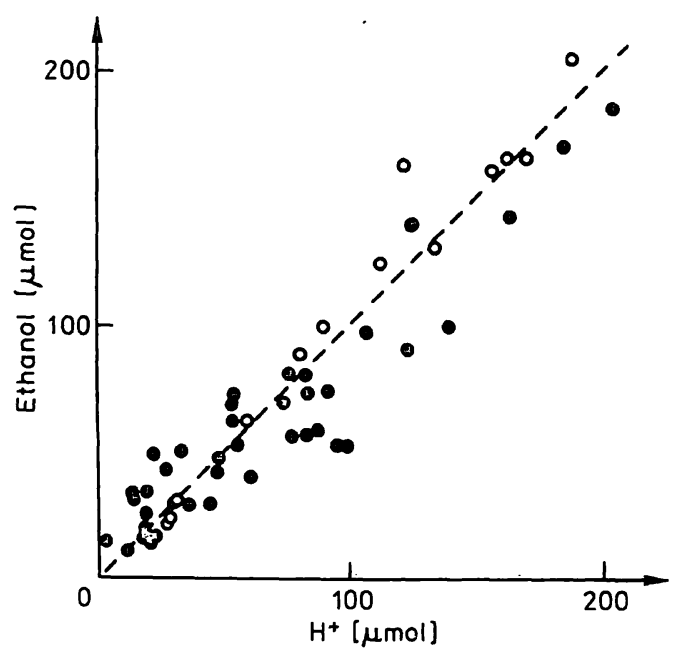

Fig. 1. Equimolar production of ethanol and $\mathrm{H}^{+}$following hydrolysis of $\mathrm{N}$-acetyl- $L$-tyrosine ethyl ester using faecal suspension $(\bullet)$ or crystalline bovine chymotrypsin (o).

Reaction mixture: $50 \mathrm{mmol} / 1$ tris buffer pH $9.0 \mathrm{con}$ taining $50 \mathrm{mmol} / 1 \mathrm{CaCl}_{2}, 500 \mathrm{mmol} / 1 \mathrm{NaCl}, 37 \mathrm{mmol} / 1$ $\mathrm{N}$-acetyl- $L$-tyrosine ethyl ester and $200 \mathrm{ml} / \mathrm{l}$ dimethylsulfoxide. Total volume $25 \mathrm{ml}$.

Incubation in sealed tubes at $25^{\circ} \mathrm{C}$ with constant agitation. After 15 minutes an aliquot was precipitated with trichloroacetic acid (final concentration $0.3 \mathrm{~mol} / \mathrm{l}$ ) for ethanol determination by the alcohol dehydrogenase method. $\mathrm{H}^{+}$liberated was assayed by immediate back titration of the incubation mixture to $\mathrm{pH} 9.0$ using $10 \mathrm{mmol} / 1 \mathrm{NaOH}$.

Regression line: $y=1.01 x-2, r=0.90, n=40$ faecal samples +14 chymotrypsin standards. test the requirement for sufficient faecal (particle) concentration and continuous agitation cannot be satisfied.

\section{Establishing optimal conditions}

Choice of solvent for $N$-acetyl-L-tyrosine ethyl ester $\mathrm{N}$-acetyl- $L$-tyrosine ethyl ester is not water soluble. The usual solvent, methanol, cannort be used since alcohol dehydrogenase is not sufficiently ethanol-specific. $\mathrm{N}$-acetyl- $L$-tyrosine ethyl ester is however, very soluble in dimethylsulfoxide. In the conventional titrimetric assay, dimethylsulfoxide, at our chosen final concentration of $200 \mathrm{ml} / 1$, leads to $60-70 \%$ enhancement of both faecal and pure bovine chymotrypsin activity (fig. 2). Since the faecal enzyme concentration is calibrated using bovine chymotrypsin, this stimulation by dimethylsulfoxide has no influence on the final result.

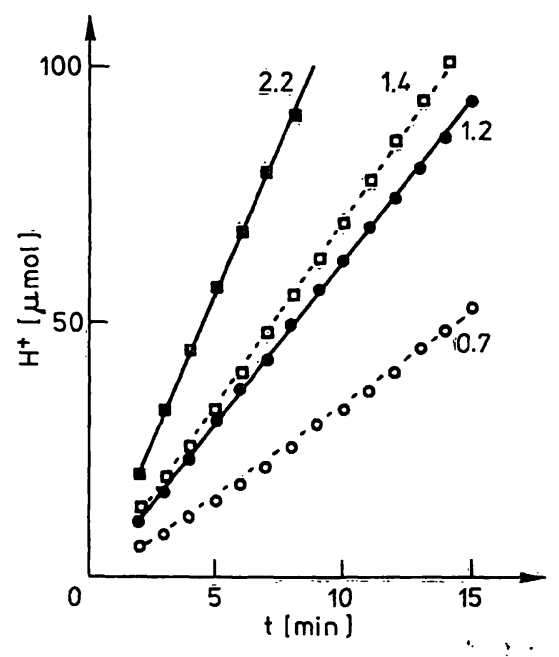

Fig. 2. pH-stat titration of faecal (०๑) and.bovine chymotrypsin (av), with methanol (open symbols) or dimethylsulfoxide (solid symbols) as the solvent. N-acetyl- $L$-tyrosine ethyl ester concentration constant at $20 \mathrm{mmol} / 1$. Other reaction conditions as with the standard titrimetric procedure. The numbers indicate the slopes of the various titration curves.

\section{Spontaneous hydrolysis of $N$-acetyl-L-tyrosine ethyl ester}

During the incubation at $\mathrm{pH} 9$ there is virtually no spon= - taneous hydrolysis of the substrate, however, once in trichloroacetic acid, there is a time-and concentrationdependent release of ethanol (fig. 3). In perchloric acid, this effect is even more evident. To give an adequate inactivation and precipitation of the test reagents the minimum concentration of trichloroacetic acid that could be used was $0.3 \mathrm{~mol} / 1$. The inclusion of a blank control tube in the assay allowed the measured enzyme activities to be corrected for the accompanying spontaneous hydrolysis. In routine conditions this correction was always less than $10 \%$ of the total activity, and can be further reduced by carrying out the assay in an ice bath. 


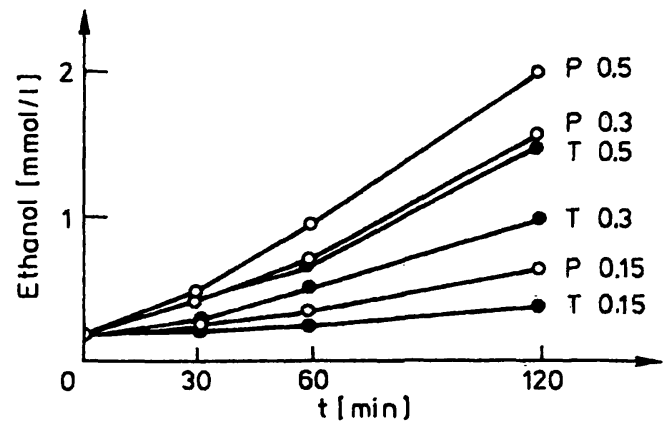

Fig. 3. Spontaneous hydrolysis of $N$-acetyl- $L$-tyrosine ethyl ester with various concentrations ( $\mathrm{mol} / \mathrm{l})$ of perchloric acid (P) or trichloroacetic acid $(\mathrm{T})$ at room temperature.

\section{Substrate concentration and $\mathrm{pH}$}

Although an $\mathrm{N}$-acetyl- $L$-tyrosine ethyl ester concentration of $14 \mathrm{mmol} / \mathrm{l}$ is used in the titrimetric procedure, we found that even at $50 \mathrm{mmol} / 1$ saturation was still not attained. As a compromise between optimal substrate concentration and economy we chose the arbitrary concentration of $37 \mathrm{mmol} / 1$ (fig. 4).

There is a broad pH-optimum around $\mathrm{pH} 9.0$ (fig. 5).

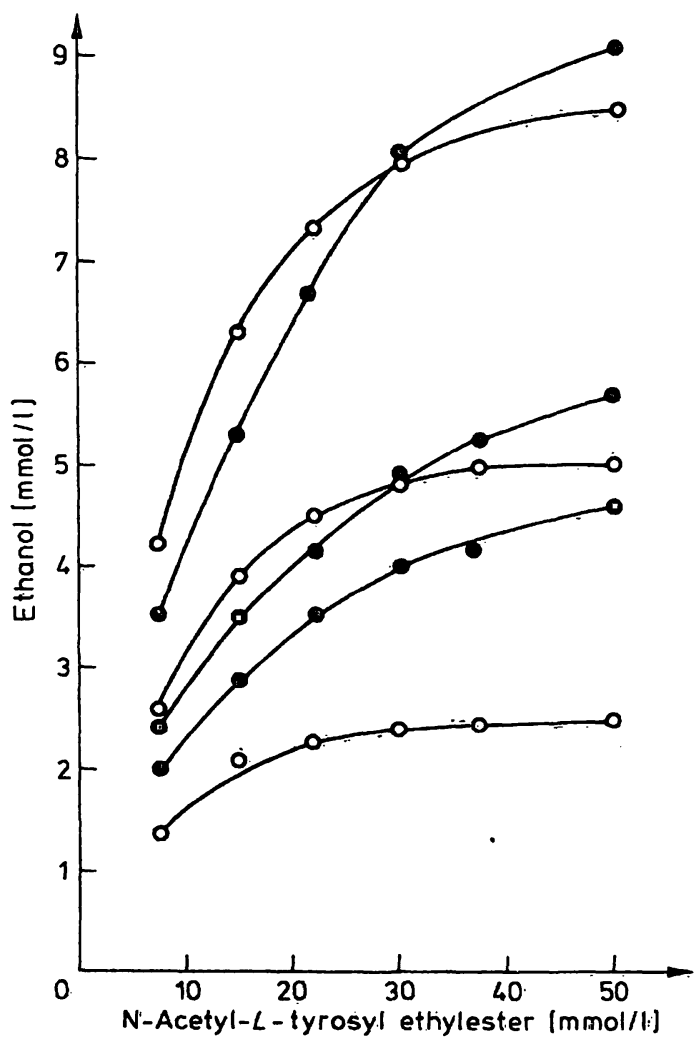

Fig. 4. Ethanol production from $N$-acetyl- $L$-tyrosine ethyl ester as a function of substrate concentration. - 0 - bovine chymotrypsin, - - faecal suspension. With the exception of varying $\mathrm{N}$-acetyl- $L$-tyrosine ethyl ester concentrations the test procedure was acc. to our "final test procedure".

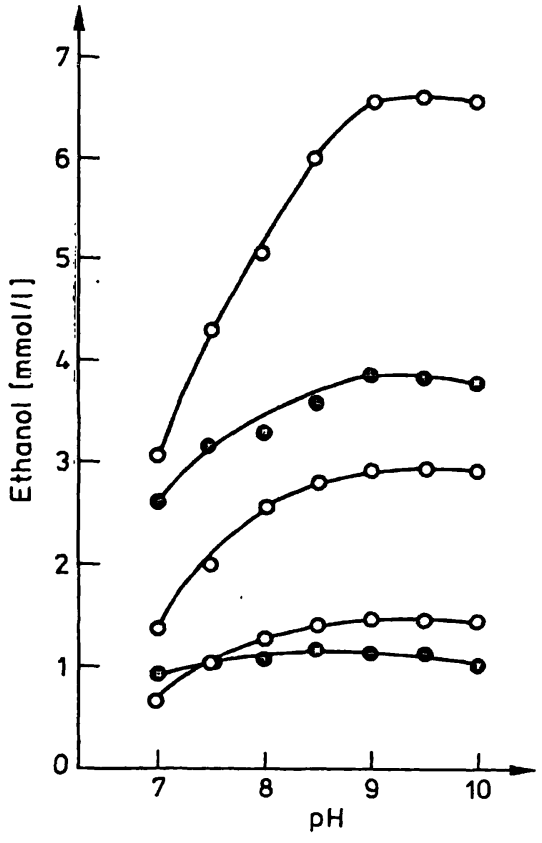

Fig. 5. pH dependence of the enzymatic hydrolysis of N-acetyl$L$-tyrosine ethyl ester. - o- bovine chymotrypsin, - - faecal suspension. The test procedure was acc. to our "final test procedure" using tris buffer with varying $\mathrm{pH}$.

\section{Final test procedure}

Suspend approximately $1 \mathrm{~g}$ faeces (accurately weighed for final correction) in $20 \mathrm{ml}$ of saline $(0.15 \mathrm{~mol} / 1$ $\mathrm{NaCl}$ ) and allow to stand overnight in a refrigerator in closed tubes.

Mix thoroughly (Whirlmix). Dilute $1 \mathrm{ml}$ faecal suspension with $4 \mathrm{ml}$ saline to give a final concentration of faeces of about $10 \mathrm{mg} / \mathrm{ml}$. Use large bore pipette tips for all sampling of stool suspension (for example cut a Marburg pipette tip by $4 \mathrm{~mm}$ before use). Prepare reagents acc. to "materials".

Mix $1 \mathrm{ml}$ of diluted faecal suspension (as well as $1 \mathrm{ml}$ chymotrypsin standard dilution $(5 \mathrm{mg} / \mathrm{l})$ and $1 \mathrm{ml}$ saline blank respectively) with $3 \mathrm{ml}$ buffer solution ${ }^{2}$ ). Start the reaction by the addition of $1 \mathrm{ml}$ substrate solution. All tests are run in duplicate. Seal the tubes and incubate 15 minutes at $25{ }^{\circ} \mathrm{C}$ with continual gentle shaking. Stop the reaction by addition of $0.5 \mathrm{ml}$ precipitant. Centrifuge at $2000 \mathrm{~g}$ for 10 minutes. For immediate determination of the ethanol concentration mix $25 \mu \mathrm{l}$ of the supernatant with $1 \mathrm{ml}$ alcohol reagent mixture prepared according to the manufacturer's instructions. Results are given as chymotrypsin per wet weight of faeces $(\mu \mathrm{g} / \mathrm{g})$. The calculation is as follows:

Chymotrypsin $[\mu \mathrm{g} / \mathrm{g}$ faeces $]=\frac{\text { ASample }}{\text { A Standard }_{\text {Sta }}} \times 5 \times 100$

$5=$ Concentration of standard $(\mathrm{mg} / \mathrm{l})$ $100=$ Dilution of faeces

${ }^{2}$ ) The total volume of the reaction mixture should not be further reduced, since addition of too small a quantity of faeces would not provide a representative proportion of chymotrypsin-active particles. 
All results are corrected for the exact weight of the stool portion assayed.

Reference values: As with the titrimetric procedure values below $120 \mu \mathrm{g} / \mathrm{g}$ indicate probability of pancreatic deficiency.

\section{Linearity and precision}

The method as described shows good linearity as a function of incubation time (fig. 6) as well as of faecal or chymotrypsin concentration (fig. 7).

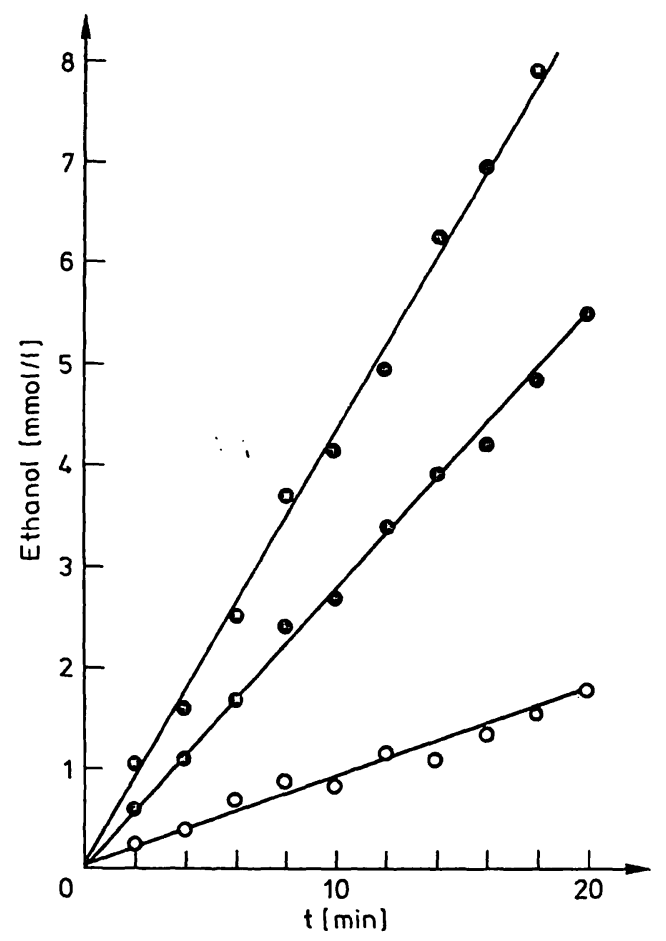

Fig. 6. Time course of ethanol production from $\mathrm{N}$-acetyl- $L$ tyrosine ethyl ester by faecal suspension $(\bullet)$ or bovine chymotrypsin (o) under our standard conditions.

The day to day coefficient of variation for three different stools was as follows:

\begin{tabular}{llll}
\hline Stool & $\overline{\mathrm{x}}(\mu \mathrm{g} / \mathrm{g})$ & $\mathrm{CV}(\%)$ & $\mathrm{N}$ \\
\hline I & 68 & 5.0 & 10 \\
II & 294 & 5.5 & 10 \\
III & 742 & 4.6 & 10 \\
\hline
\end{tabular}

The within-day precision calculated from 150 routinely performed duplicate assays was $11 \%$, the activities ranging from 20 to $2000 \mu \mathrm{g} / \mathrm{g}$.

\section{References}

1. Schlaeger, R. \& Röhr, A. (1980) J. Clin. Chem. Clin. Biochem, 18, 695-696.

2. Haverback, B. J., Dyce, B. J., Gutentag, Ph. J. \& Montgomery, D. W. (1963) Gastroenterology 44, 588-597.

3. Schneider, R., Dürr, H. K. \& Bode, J. Ch. (1976) Verh. Dtsch. Ges. Inn. Med. 82, 952-954.

4. Löffler, A., Ernst, R., Miederer, S. E. \& Stadelmann, O. (1975) Med. Klinik 70, 1755-1758.

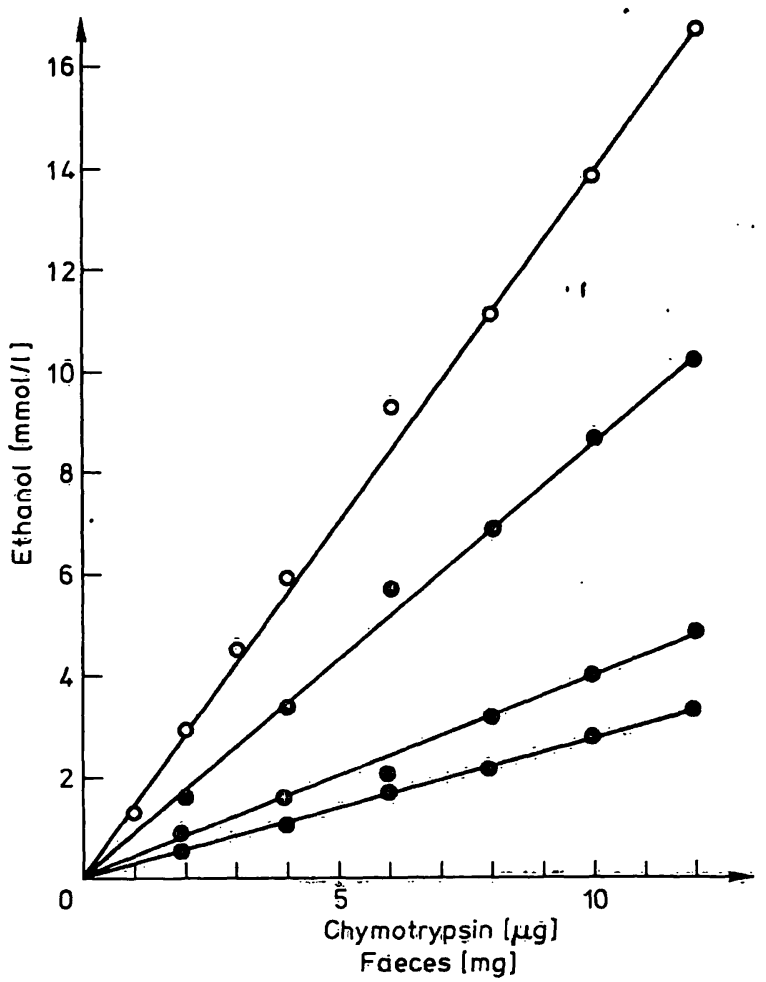

Fig. 7. Effect of the amount of enzyme added per test on ethanol production from $N=a c e t y l-L$-tyrosine ethyl ester

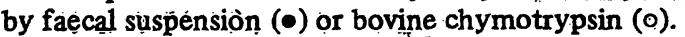
Incubation for 15 minutes at $25^{\circ} \mathrm{C}$.

\section{Conclusion}

Our photometric method makes use of the well established substrate $\mathrm{N}$-acetyl- $\dot{L}$-tyrosine ethyl ester, as well as uncentrifuged faecal suspension. The reaction product, ethanol, can be measured easily in the clear trichloroacetic acid supernatant without any loss in recovery. Therefore the activity determined in faecal suspension compared to bovine chymotrypsin as a standard is similar to that obtained by the titration method. All previous clinical experience with regard to sensitivity, specificity and reference region can be used.

The test is linear over a wide range of activities. Large series of determinations can be made relatively quickly without special laboratory equipment. The procedure in our hands has successfully proved itself over two years.

\section{Acknowledgement}

We acknowledge the expert technical support of Mrs. $\ddot{R}$. Reuter and Mrs. M. Schütze.

5. Willig, F. \& Körber, W. (1967) Z. Gastroenterol. 5, 33-36.

6. Imondi, A. R., Stradley, R. P., Butler, E. R. \& Wolgemuth, R. L. (1973) Anal. Biochem. 54, 199-204.

7. Bornschein, W. (1977) Leber, Magen, Dàrm 7, 334-336

8. Büchèr, Th. \& Redetzki, H. (1951) Klin. Wochenșchr. 29 , 615-618.

PD Dr. R. Schlaeger

Zentrallabor-Krankenhaus Wandsbek

Alphonsstr. 14

D-2000 Hamburg 70

$\rightarrow$

J. Clin. Chem. Clin. Biochem. / Vol. 20, 1982 / No. 3 